\title{
Studi Deskripsi Tingkat Literasi Keuangan \\ (Pada Mahasiswa Program Studi Akuntansi Fakultas Ekonomi UMRAH)
}

\author{
Descriptive Study of Financial Literacy \\ (In Students of the Accounting Study Program, Faculty Of Economics, UMRAH)
}

\author{
Jack Febriand Adel ${ }^{1}$, Kiki Wulandari² \\ 1 Universitas Maritim Raja Ali Haji \\ 2Universitas Maritim Raja Ali Haji \\ Email: jackfebriandadel@umrah.ac.id
}

\begin{abstract}
ABSTRAK
Literasi keuangan merupakan rangkaian proses atau kegiatan untuk meningkatkan pengetahuan, keterampilan konsumen dan masyarakat luas sehingga mampu mengelola keuangan dengan lebih baik, sesuai dengan yang dibutuhkan dan memberikan manfaat. Penelitian ini bertujuan untuk mendeskripsikan tingkat literasi keuangan mahasiswa. Penelitian ini menggunakan pendekatan kuantitatif deskriptif yang mencoba mendeskripsikan, mendeskripsikan dan menginterpretasikan suatu fenomena yang terjadi sesuai dengan data yang ada di lapangan. Lokasi penelitian berada di Program Studi Akuntansi Fakultas Ekonomi Universitas Maritim Raja Ali Haji (UMRAH), Kota Tanjungpinang. Waktu proses pelaksanaan penelitian dilakukan selama 8 (sembilan) bulan, sesuai dengan masa pengajuan penelitian Skema Penelitian Unggulan Perguruan Tinggi. Kesimpulan dari kegiatan Riset Unggulan Perguruan Tinggi dengan judul STUDI DESKRIPSI TINGKAT LITERASI KEUANGAN (Untuk Mahasiswa Program Studi Akuntansi Fakultas Ekonomi UMRAH) yang dilaksanakan pada tahun 2020 ini secara keseluruhan tingkat literasi keuangan responden masih rendah. pengetahuan literasi keuangan.

Kata Kunci: literasi keuangan, mahasiswa, studi deskripsi
\end{abstract}

\begin{abstract}
Financial literacy is a series of processes or activities to increase the knowledge, skills of consumers and the wider community so that they are able to manage finances better, according to what they need and provide benefits. This study aims to describe the level of student financial literacy. This research uses a descriptive quantitative approach that tries to describe, describe and interpret a phenomenon that occurs in accordance with existing data in the field. The research location is in the Accounting Study Program, Faculty of Economics, Raja Ali Haji Maritime University (UMRAH), Tanjungpinang City. The time of the research implementation process was carried out for 8 (nine) months, according to the research submission period of the Higher Education Leading Research Scheme. The conclusion of the Higher Education Leading Research activities with the title STUDY DESCRIPTION OF FINANCIAL LITERATION LEVELS (For Accounting Study Program Students of the UMRAH Faculty of Economics) which was carried out in 2020 is that the overall level of financial literacy of respondents still has low knowledge of financial literacy.

Keywords: financial literacy, students, descriptive study
\end{abstract}




\section{PENDAHULUAN}

Mahasiswa yang berkesempatan mengenyam pendidikan di perguruan tinggi, terutama pada Fakultas Ekonomi, tentunya memperoleh kesempatan memliki pengetauan keuangan yang lebih dibandingkan mahasiswa yang berada pada fakultas lainnya. Kesempatan memperoleh pengetahuan tersebut tentunya memiliki impikasi terhadap pengetahuan keuangan mereka. Pembelajaran di perguruan tinggi sangat berperan penting dalam proses pembentukan literasi finansial mahasiswa. Melalui kombinasi berbagai metode pengajaran, media dan sumber belajar yang direncanakan dengan baik dan sesuai dengan kompetensi, diharapkan mampu memberikan bekal kepada mahasiswa untuk memiliki kecakapan di bidang keuangan, sehingga mahasiswa menjadi siap dan mampu menghadapi kehidupan mereka saat ini maupun masa depan yang semakin kompleks. Mahasiswa merupakan salah satu komponen masyarakat yang jumlahnya cukup besar serta berperan penting bagi perubahan bangsa (agent of change).

Literasi keuangan dewasa ini sangat diperlukan agar individu dapat bijak dan efektif dalam mengelola keuangannya, sehingga tidak terkesan konsumtif, hanya memikirkan kepuasan jangka pendek tanpa memperhatikan kesejahteraan jangka panjangnya. Namun, kenyataannya literasi keuangan Indonesia masih rendah jika dibandingkan dengan negara-negara di kawasan ASEAN lainnya. Hasil survei nasional tahun 2019 yang dilakukan Otoritas Jasa Keuangan, menunjukkan Indeks Literasi Keuangan Indonesia sebesar 29.66\%.

Manajemen atau pengelolaan keuangan menjadi penting dikarenakan sebagai tolak ukur dalam perilaku penggunaan keuangan. Kesulitan keuangan yang dialami oleh individu bukan disebabkan oleh rendahnya penghasilan akan tetapi disebabkan oleh rendahnya pengelolaan keuangan.

\section{LANDASAN TEORI}

\section{Literasi Keuangan}

Literasi keuangan merupakan pengetahuan atau kemampuan untuk mengelola keuangan. Menurut Otoritas Jasa Keuangan (OJK), literasi keuangan adalah rangkaian proses atau aktivitas untuk meningkatkan pengetahuan, keyakinan, dan keterampilan konsumen serta masyarakat luas, sehingga mereka mampu mengelola keuangan dengan baik. Literasi keuangan dewasa ini sangat diperlukan agar individu dapat bijak dan efektif dalam mengelola keuangannya, sehingga tidak terkesan konsumtif, hanya memikirkan kepuasan jangka pendek tanpa memperhatikan kesejahteraan jangka panjangnya. Namun, kenyataannya literasi keuangan Indonesia masih rendah jika dibandingkan dengan negaranegara di kawasan ASEAN lainnya. Hasil survei nasional tahun 2019 yang dilakukan Otoritas Jasa Keuangan, menunjukkan Indeks Literasi Keuangan Indonesia sebesar 29.66\%. Untuk meningkatkan pemahaman masyarakat tentang literasi keuangan, Otoritas Jasa Kuangan membentuk program guna meningkatkan literasi keuangan, yaitu melalui Strategi Nasional Literasi Keuangan Indonseia. Dalam Strategi Nasional Literasi Keuangan Indonesia memiliki beberapa pilar, yaitu: 1) Edukasi dan Kampanye Nasional, 2) penguatan infrastruktur, 3) pengembangan produk dan layanan.

Mahasiswa merupakan salah satu komponen masyarakat yang jumlahnya cukup besar serta berperan penting bagi perubahan bangsa (agent of change). Mahasiswa yang berkesempatan mengenyam pendidikan di perguruan tinggi, terutama pada Fakultas Ekonomi, tentunya memperoleh kesempatan memliki pengetauan keuangan yang lebih dibandingkan mahasiswa-mahasiswa yang berada pada fakultas lainnya. Kesempatan memperoleh pengetahuan tersebut tentunya memiliki impikasi terhadap pengetahuan keuangan mereka. Pembelajaran di perguruan tinggi sangat berperan penting dalam proses pembentukan literasi finansial mahasiswa. Melalui kombinasi berbagai metode pengajaran, media dan sumber belajar yang direncanakan dengan baik dan sesuai dengan kompetensi, diharapkan mampu memberikan bekal kepada mahasiswa untuk memiliki kecakapan di bidang keuangan, sehingga mahasiswa menjadi siap dan mampu menghadapi kehidupan mereka saat ini maupun masa depan yang semakin kompleks. Manajemen atau pengelolaan keuangan menjadi penting dikarenakan sebagai tolak ukur dalam perilaku penggunaan keuangan. Kesulitan keuangan yang dialami oleh individu bukan disebabkan oleh rendahnya penghasilan akan tetapi disebabkan oleh rendahnya pengelolaan keuangan.

\section{Tingkat Literasi Keuangan}

Tingkat literasi keuangan yang tinggi merupakan kebutuhan dasar bagi setiap orang agar terhindar dari masalah keuangan (Drentea, 2000). Kesulitan keuangan bukan disebabkan dari 
pendapatan semata (rendahnya pendapatan), kesulitan keuangan juga dapat muncul jika terjadi kesalahan dalam pengelolaan keuangan seperti kesalahan penggunaan kredit, tidak adanya perencanaan keuangan dan tidak memiliki tabungan. Sehingga memiliki literasi keuangan yang tinggi merupakan hal vital untuk mendapatkan kehidupan yang sejahtera (Kim \& Garman, 2003).

Edukasi finansial (financial education) dijadikan sebagai alat mengatasi permasalahan rendahnya tingkat melek keuangan (Shockey, 2002). Namun masih merupakan tantangan besar diterapkan di Indonesia. Edukasi finansial adalah proses panjang yang memacu individu untuk memiliki rencana keuangan di masa depan demi mendapatkan kesejahteraan sesuai dengan pola dan gaya hidup yang mereka jalani (Joo \& Garman, 1998). Sementara di Indonesia sendiri pendidikan keuangan pribadi (personal finance) masih jarang ditemui baik itu di sekolah sampai perguruan tinggi.

Pendidikan sangat berperan penting dalam pembentukan literasi finansial, baik pendidikan informal di lingkungan keluarga maupun pendidikan formal di lingkungan perguruan tinggi. Dalam lingkungan keluarga, tingkat literasi finansial ditentukan oleh peran orang tua dalam memberikan dukungan berupa pendidikan keuangan (Lusardi, Mitchell and Curto, 2010). Pembelajaran di perguruan tinggi sangat berperan penting dalam proses pembentukan literasi finansial mahasiswa. Pembelajaran yang efektif dan efisien akan membantu mahasiswa memiliki kemampuan memahami, menilai, dan bertindak dalam kepentingan keuangan mereka.

Chen and Volpe (1998) mengkategorikan literasi keuangan menjadi 3 kelompok, yaitu

1. $<60 \%$ yang berarti responden memiliki pengetahuan tentang keuangan yang rendah

2. $60 \%-79 \%$, yang berarti responden memiliki pengetahuan tentang keuangan yang sedang

3. $>80 \%$ yang menunjukan bahwa responden memiliki pengetahuan keuangan yang tinggi.

Chen and Volpe (1998) menjabarkan literasi keuangan ke dalam 4 dimensi yaitu:

1. Manajemen keuangan pribadi (personal finance) merupakan proses perencanaan dan pengendalian keuangan dari unit individu atau keluarga

2. Bentuk simpanan di Bank yang dapat dilakukan dalam bentuk tabungan (sebagian pendapatan mastyarakat yang tidak dibelanjakan disimpan sebagai cadangan guna berjaga-jaga dalam jangka pendek), deposito berjangka (simpanan pada bank yang penarikannya hanya dapat dilakukan dalam jangka waktu tertentu), sertifikat deposito (deposito berjangka yang bukti simpanannya dapat diperdagangkan), dan giro (simpanan pada bank yang dapat digunakan sebagai alat pembayaran).

3. Asuransi adalah salah satu bentuk pengendalian resiko yang dilakukan dengan cara mengalihkan/transfer risiko dari satu pihak ke pihak lain (dalam hal ini adalah perusahaan asuransi). Definisi asuransi yang lain adalah merupakan suatu pelimpahan resiko dar pihak pertama kepada pihak lain.

4. Investasi merupakan suatu bentuk pengalokasian pendapatan yang dilakukan saat ini untuk memperoleh manfaat keuntungan (return) di kemudian hari yang bisa melebihi modal investasi yang dikeluarkan saat ini.

\section{METODA PENELITIAN \\ Jenis Penelitian}

Jenis Penelitian ini menggunakan pendekatan kuantitatif yang bersifat deskriptif yang mencoba mengambarkan, memaparkan dan menafsirkan suatu fenomena yang terjadi sesuai dengan data yang ada dilapangan.

\section{Lokasi Tempat dan Waktu Penelitian}

Penelitian ini memilih lokasi di Program Studi Akuntansi Fakultas Ekonomi Universitas Maritim Raja Ali Haji (UMRAH) Kota Tanjungpinang. Waktu proses pelaksanaan penelitian dilakukan selama 8 (sembilan) bulan, sesuai periode pengajuan penelitian Skema Penelitian Unggulan Perguruan Tinggi.

\section{Sumber Data Penelitian}

Data yang digunakan dalam penelitian ini dapat dikelompokkan menjadi 2 (dua) jenis, yaitu:

1. Data Primer; data-data yang diperoleh melalui kuisioner.

2. Data Sekunder; data yang diambil melalui study kepustakaan yakni data dari dokumendokumen. 


\section{Teknik Pengumpulan Data}

Tujuan teknik pengumpulan data dilakukan peneliti adalah untuk melengkapi informasi dan sumber data-data yang dibutuhkan selama pengolahan data-data penelitian, baik data utama maupun data pendukung yakni data yang bersifat primer maupun sekunder. Memperoleh data yang sesuai dengan rumusan masalah dan tujuan penelitian ini, maka teknik pengumpulan dilakukan peneliti menggunakan 4 (empat) teknik pengumpulan data, antara lain:

1. Observasi merupakan salah satu teknik pengumpulan data yang tidak hanya mengukur sikap dari responden (wawancara dan angket) namun juga dapat digunakan untuk merekam berbagai fenomena yang terjadi (situasi, kondisi). Dalam observasi ini, peneliti secara langsung terlibat dalam kegiatan sehari-hari orang atau situasi yang diamati sebagai sumber data.

2. Pelaksanaan pengumpulan data primer melalui kuisioner.

3. Studi Kepustakaan; suatu bentuk pengumpulan data melalui buku yang sesuai dengan penelian atau literatur, hasil penelitian terdahulu.

\section{Populasi dan Sampel Penelitian}

Populasi penelitian ini adalah Mahasiswa Akuntansi Program Studi Akuntansi Fakultas Ekonomi UMRAH sedangkan sampel penelitian diambil menggunakan pendekatan probability sampling dengan teknik simple random sampling.

\section{Metode Analisis Data Penelitian}

Tingkatan diperoleh dengan teknik analisis data sebagai berikut:

1. Menghitung Skor tertinggi dan Skor terendah

2. Untuk mengetahui tingkat kategori tersebut, selanjutnya skor dikuantifikasikan dengan kategori literasi keuangan tingkatan yang digunakan OJK yaitu:
a. Well literate dan Suffice literate
b. Less literate.

3. Untuk mengetahui literasi keuangan keseluruhan dengan analisis deskriptif persentase pada Well/Suffice Litterate dikuantifikasikan dengan kategori literasi keuangan Chen and Volpe (1998), yaitu :

a. $<60 \%$ yang berarti responden memiliki pengetahuan tentang keuangan yang rendah

b. $60 \%-79 \%$, yang berarti responden memiliki pengetahuan tentang keuangan yang sedang

c. $80 \%$ yang mengambarkan responden memiliki pengetahuan tentang keuangan yang tinggi.

\section{HASIL DAN PEMBAHASAN}

Hasil

Hasil penelitian tingkat literasi keuangan mahasiswa Jurusan Akuntansi Fakultas Ekonomi Universitas Maritim Raja Ali Haji, akan tergambar dari hasil pengisian kuesioner. Responden terdiri dari mahasiswa semester 5 dan Semester 7. Dari total 124 kuesioner yang telah diisi, seluruhnya kuesioner layak digunakan untuk pengolahan data lebih lanjut. Selanjutnya skor dikuantifikasikan dengan kategori literasi keuangan OJK:

\begin{tabular}{|c|c|c|}
\hline \multicolumn{3}{|l|}{ Pengetahuan Mengenai Lembaga Jasa Keuangan } \\
\hline Perbankan & $72.58 \%$ & Less Literate \\
\hline $\begin{array}{l}\text { Asuransi, Pasar Modal, Lembaga Pembiayaan, Dana } \\
\text { Pensiun dan Pergadaian }\end{array}$ & $22.58 \%$ & Suffice Literate \\
\hline $\begin{array}{l}\text { Lembaga Jasa Keuangan Lainnya, Obligasi dan Reksa } \\
\text { Dana }\end{array}$ & $4.84 \%$ & Well Literate \\
\hline \multicolumn{3}{|l|}{ Pengetahuan Mengenai Produk Dan Layanan Jasa Keuangan } \\
\hline Tabungan & $72.58 \%$ & Less Literate \\
\hline Asuransi dan Transfer dan Jaminan/ Gadai, Kredit & $26.61 \%$ & Suffice Literate \\
\hline Program Pensiun/luran Pasti & $0.81 \%$ & Well Literate \\
\hline \multicolumn{3}{|c|}{ Pengetahuan Mengenai Karakteristik Produk Dan Layanan Jasa Keuangan } \\
\hline Paham Manfaat & $80.65 \%$ & Less Literate \\
\hline
\end{tabular}




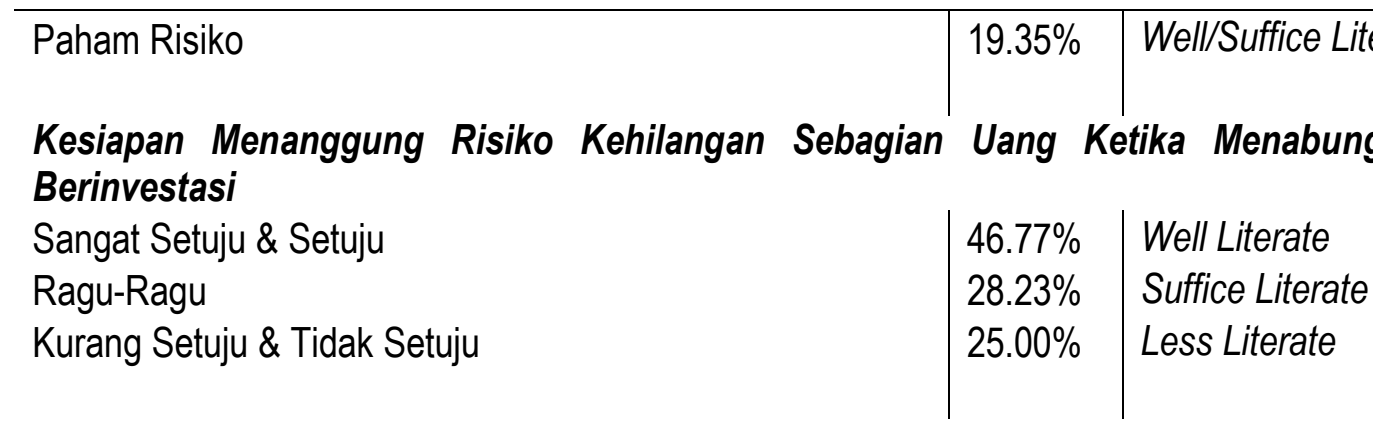

Pengetahuan Mengenai Fitur, Cara Memperoleh Produk Layanan Jasa Keuangan

Paham Fitur

$33.87 \%$ Well/Suffice Literate

Paham Cara Memperoleh

$66.13 \%$ Less Literate

Sumber Informasi Yang Mempengaruhi Keputusan Keuangan

Iklan TV dan Iklan Koran

$54.03 \%$

Less Literate

Saran Dari Teman

$16.13 \%$

Suffice Literate

Program TV Atau Radio dan Kantor Cabang LJK

$29.84 \%$

Well Literate

Pengetahuan Mengenai Biaya Dan Denda Produk Dan Layanan Jasa Keuangan

Paham Biaya

$71.77 \%$

Well/Suffice Literate

Paham Denda

$28.23 \%$

Less Literate

Pengetahuan Mengenai Hak Dan Kewajiban

Hak

Kewajiban

Less Literate

$51.61 \%$

Well/Suffice Literate

Keterampilan Dalam Perhitungan Sederhana

Merasa Mampu Menghitung

Menghitung Dengan Benar

$48.39 \%$

Less Literate

$51.61 \%$

Well/Suffice Literate

Keterampilan Dalam Perhitungan Suku Bunga

Merasa Mampu Menghitung

Menghitung Suku Bunga Dengan Benar

$53.23 \%$

Less Literate

$46.77 \%$ Well/Suffice Literate

Keterampilan Dalam Perhitungan Inflasi

Merasa Mampu Menghitung

Menghitung Inflasi Dengan Benar

62.10\% Less Literate

$37.90 \%$ Well/Suffice Literate

Keyakinan Terhadap Lembaga Jasa Keuangan

Perbankan dan Pergadaian

Asuransi dan Lembaga Pembiayaan

Dana Pensiun dan Pasar Modal

$79.03 \%$

$12.10 \%$

$8.87 \%$
Less Literate

Suffice Literate

Well Literate

Menetapkan Rencana Keuangan Jangka Panjang Dan Berusaha Mencapainya

Sangat Setuju dan Setuju

Ragu-Ragu

Tidak Setuju dan Sangat Tidak Setuju

$96.77 \%$

$2.42 \%$

$0.81 \%$
Well Literate

Suffice Literate

Less Literate 


\section{Upaya Untuk Mencapai Tujuan Keuangan}

Menabung

Menyusun Rencana Keuangan

41.94\% Less Literate

$58.06 \%$ Well/Suffice Literate

Tabel berikut mengambarkan hasil analisis secara keseluruhan dikuantifikasikan dengan kategori literasi keuangan Chen and Volpe (1998):

$\begin{array}{ll}\text { Well/Suffice Literate } & 52.42 \% \\ \text { Less Literate } & 47.58 \%\end{array}$

Berdasarkan tabel diatas, tingkat literasi keuangan Well/Suffice Literate adalah $52.42 \%$, yang berarti responden memiliki pengetahuan tentang keuangan yang rendah.

\section{Pembahasan}

Berdasarkan analisis diatas, tingkat literasi keuangan responden secara keseluruhan masih memiliki pengetahuan tentang literasi keuangan yang rendah.

Pengetahuan terkait literasi keuangan yang rendah (Less Literate) adalah:

1. Pengetahuan Mengenai Lembaga Jasa Keuangan

2. Pengetahuan Mengenai Produk Dan Layanan Jasa Keuangan

3. Pengetahuan Mengenai Karakteristik Produk Dan Layanan Jasa Keuangan

4. Pengetahuan Mengenai Fitur Dan Cara Memperoleh Produk Dan Layanan Jasa Keuangan

5. Sumber Informasi Yang Mempengaruhi Keputusan Keuangan

6. Keterampilan Dalam Perhitungan Suku Bunga

7. Keterampilan Dalam Perhitungan Inflasi

8. Keyakinan Terhadap Lembaga Jasa Keuangan

Pengetahuan terkait literasi keuangan yang tinggi/sedang (Well/Suffice Literate) adalah:

1. Kesiapan Menanggung Risiko Kehilangan Sebagian Uang Ketika Menabung Atau Berinvestasi

2. Pengetahuan Mengenai Biaya Dan Denda Produk Dan Layanan Jasa Keuangan

3. Pengetahuan Mengenai Hak Dan Kewajiban

4. Keterampilan Dalam Perhitungan Sederhana

5. Menetapkan Rencana Keuangan Jangka Panjang Dan Berusaha Mencapainya

6. Upaya Untuk Mencapai Tujuan Keuangan

\section{KESIMPULAN DAN SARAN}

1. Tingkat literasi keuangan responden secara keseluruhan masih memiliki pengetahuan tentang literasi keuangan yang rendah.

Saran untuk penelitian selanjutnya:

1. Menambah cakupan penelitian dengan menambahkan program studi lainnya.

2. Menambah jumlah responden

3. Menggunakan metoda penelitian True Experimental dan/atau Quasi Experimental.

\section{DAFTAR PUSTAKA}

Chen, H., \& Volpe, R. P. (1998). An Analysis Of Financial Literacy Among College Students. Financial Services Review, 7(1), 107-128.

Drentea, P. (2000). Age, debt, and anxiety. Journal of Health and Social Behavior, 41

Joo, S., \& Garman, E. T. (1998). Personal financial wellness maybe the missing factor in understanding and reducing worker absenteenism. Personal Finance and Worker Productivity, 2(2).

Kim, J., \& Garman, E. T. (2003). Financial stress and absenteeism: An empirically derived model, Financial Counseling and Planning, 14 (1).

Lusardi, A., Mitchell, O.S., and Curto, V. (2010). Financial Literacy among the young evidence and implications for consumer policy. Journal of Consumer Affairs 44 (2).

Otoritas Jasa Keuangan. (20190 Survei Nasional Literasi Dan Inklusi Keuangan 2019.

Shockey, S. S. (2002). Low-wealth adult's financial literacy. Money management behavior and associates factors, including critical thinking. Unpublished doctoral dissertation, The Ohio State University (AAT 3039524). 